\title{
Amelioration of $\mathrm{PM}_{2.5}$-induced lung toxicity in rats by nutritional supplementation with fish oil and Vitamin E
}

\author{
Juan Li ${ }^{\dagger}$, Hang Li ${ }^{\dagger}$, Haibin Li, Weili Guo, Zhen An, Xiang Zeng, Wen Li, Huijun Li, Jie Song and Weidong Wu*
}

\begin{abstract}
Background: Exposure to fine particulate matter $\left(\mathrm{PM}_{2.5}\right)$ has been associated with respiratory morbidity and mortality. Identification of interventional measures that are efficacious against $\mathrm{PM}_{2.5}$-induced toxicity may provide public health benefits. This study examined the inhibitory effects of nutritional supplementation with fish oil as a source of omega-3 fatty acids and vitamin E (Vit E) on $\mathrm{PM}_{2.5}$-induced lung toxicity in rats.
\end{abstract}

Method: Sixty four male Sprague Dawley rats were gavaged with phosphate buffered saline (PBS), corn oil (5 ml/ $\mathrm{kg})$, fish oil $(150 \mathrm{mg} / \mathrm{kg})$, or Vit E $(75 \mathrm{mg} / \mathrm{kg})$, respectively, once a day for 21 consecutive days prior to intratracheal instillation of $\mathrm{PM}_{2.5}(10 \mathrm{mg} / \mathrm{kg})$ every other day for a total of 3 times. Serum and bronchoalveolar lavage fluids (BALFs) were collected $24 \mathrm{~h}$ after the last instillation of $\mathrm{PM}_{2.5}$. Levels of total proteins (TP), lactate dehydrogenase $(\mathrm{LDH})$, superoxide dismutase (SOD), 8-epi-prostaglandin F2a (8-epi-PGF2a), interleukin-1 $\beta$ (IL-1 $\beta)$, C-reactive protein (CRP), IL-6, and tumor necrosis factor-a (TNF-a) were analyzed for markers of cell injury and inflammation. Additionally, histological alterations of lung tissues were examined by hematoxylin-eosin staining.

Result: Exposure to $\mathrm{PM}_{2.5}$ resulted in lung toxicity, represented as increased levels of total proteins, LDH, 8-epiPGF2 $\alpha, I L-1 \beta$ and TNF- $\alpha$, and increased infiltration of inflammatory cells, and decreased SOD in the BALFs, and systemic inflammation, as evinced by increased levels of CRP and IL-6 in serum. Strikingly, supplementation with fish oil but not Vit E significantly ameliorated $\mathrm{PM}_{2.5}$-induced lung toxicity and systemic inflammation.

Conclusion: $\mathrm{PM}_{2.5}$ exposure induces oxidative stress, lung injury and inflammation, which is ameliorated significantly by fish oil and partially by Vit E.

Keywords: $\mathrm{PM}_{2.5}$, Fish oil, Vitamin E, Lung toxicity, Inflammation, Oxidative stress

\section{Background}

Outdoor air pollution has become a major global public health concern. The frequency of haze, extreme air pollution episodes that are characterized by decreased visibility less than $10 \mathrm{~km}$ and high concentrations of $\mathrm{PM}_{2.5}$ (PM with an aerodynamic diameter less than $2.5 \mu \mathrm{m})$ and gaseous pollutants, has increased in large areas of China, including North and Central China Plains, the Yangtze River Delta, and the Pearl River Delta $[1,2]$. Ambient PM, a principal component of air pollutant, has been considered as the main contributor to

\footnotetext{
* Correspondence: wdwu2013@126.com

${ }^{\dagger}$ Juan Li and Hang Li contributed equally to this work.

International Collaborative Laboratory for Air Pollution Health Effects and Intervention, School of Public Health, Xinxiang Medical University, 601 Jinsui Street, Xinxiang 453003, Henan Province, China
}

such haze weather [3-5]. A recent study on the global burden of diseases indicated that ambient $\mathrm{PM}_{2.5}$ was the fifth-ranking mortality risk factor in 2015 [6]. In Beijing, the capital of China, a 6-year period study revealed that an increase in $10 \mu \mathrm{g} / \mathrm{m}^{3} \mathrm{PM}_{2.5}$ results in an elevation of $4.60 \%$ (95\% CI $3.84-4.60 \%$ ) and $4.48 \%$ (95\% CI $3.53-$ $5.41 \%)$ for respiratory mortality and morbidity, respectively.

Due to its small size and large surface area, $\mathrm{PM}_{2.5-}$ absorbs diverse organic, metallic and biological components and easily deposits in alveoli, leading to adverse health effects [7]. Extensive epidemiological and toxicological studies have shown that $\mathrm{PM}_{2.5}$ is positively associated with the incidence of respiratory disease and the exacerbation of different respiratory disease including

(c) The Author(s). 2019 Open Access This article is distributed under the terms of the Creative Commons Attribution 4.0 International License (http://creativecommons.org/licenses/by/4.0/), which permits unrestricted use, distribution, and 
asthma [8], chronic obstructive pulmonary disease (COPD) [9], and lung cancer [10], as well as impairment of lung function [11]. Although the mechanisms underlying $\mathrm{PM}_{2.5}$-induced pulmonary disorders are not fully understood, inflammation and oxidative stress are considered to play important roles in $\mathrm{PM}_{2.5}$-induced cardiopulmonary toxicity [12].

Omega-3 polyunsaturated fatty acids (omega-3 PFAs) found in fish oil are widely used as a nutraceutical for the prevention and treatment of cardiovascular disease and dyslipidemia. Eicosapentaenoic acid (EPA) and docosahexaenoic acid (DHA), the effective constituents of omega-3 PFAs, inhibit inflammation by modulating the release of inflammatory cytokines, such as tumor necrosis factor-alpha (TNF- $\alpha$ ), interleukins and lipid mediators $[13,14]$. Fish oil is able to compete with arachidonic acid so as to reduce the production of prostaglandin and leukotrienes [15]. Additionally, EPA and DHA are able to induce the generation of anti-inflammatory lipids, inhibit the activation of pro-inflammatory signaling through nuclear factor $\kappa \mathrm{B}(\mathrm{NF} \kappa \mathrm{B})$ [16]. Vitamin $\mathrm{E}$ (Vit E) is regarded as an anti-oxidant substance that can block the development of some degenerative diseases by scavenging reactive oxygen species (ROS) [17, 18]. It refers to a group of eight fat soluble compounds that include four tocopherols and four tocotrienols, of which $\alpha$-tocopherol (used in this study) has the highest biological activity in the eight isoforms of Vit $\mathrm{E}$ and terminates free radicals reactions $[19,20]$.

Our previous study has shown that exposure to $\mathrm{PM}_{2.5}$ induces oxidative stress and inflammation [21]. Given their anti-inflammatory and antioxidant properties [22], we hypothesized that fish oil and Vit E may show protective effects against $\mathrm{PM}_{2.5}$ toxicity. Thus, in the present study, we used the animal model to evaluate the efficacy of supplementation with fish oil or Vit $E$ on $\mathrm{PM}_{2.5}$-induced lung inflammation, which would provide useful information in the design of intervention measures against $\mathrm{PM}_{2.5}$-induced lung toxicity.

\section{Materials and methods \\ Reagents}

Fish oil was purchased from Swiss company (Melbourne, Australia), corn oil from Shandong Sanxing corn technology Co., Ltd. (Shandong, China), and Vit E ( $\alpha$-tocopherol) from Sigma-Aldrich (St. Louis, USA). Fish oil, corn oil and Vit E were all certified as endotoxin free. IL-1 $\beta$, IL-6, C-reactive protein (CRP), and TNF- $\alpha$ ELISA kits were purchased from Boster Biological Technology Co., Ltd. (Wuhan, China). 8-epi-prostaglandin F2 $\alpha$ (8-epi-PGF2 $\alpha$ ) ELISA kit was purchased from Elabscience Biotechnology Co., Ltd. (Wuhan, China). Lactate dehydrogenase (LDH) and superoxide dismutase (SOD) assay kits were procured from Nanjing Jiancheng Bioengineering Institute (Nanjing, China).

\section{Animals}

Sixty four 6-8 weeks old Sprague Dawley (SD) rats (specific pathogen-free grade, male, weighing 180-220 g) were purchased from Beijing Vital River Laboratory Animal Technology Co., Ltd. (Beijing, China). Rats were acclimatized for 1 week in the animal facility $\left(19-22^{\circ} \mathrm{C}\right.$, humidity $40-70 \%, 12 / 12$-h light/dark cycle) equipped with an individual ventilated caging system prior to and during the experimental period. To avoid interference of hormonal influences with $\mathrm{PM}_{2.5}$ toxicity, we only used male rats in this study. All rats received food and water ad libitum. Animal use and care procedures were approved by the Institutional Animal Care and Use Committee of Xinxiang Medical University.

\section{$\mathrm{PM}_{2.5}$ collection and analyses}

$\mathrm{PM}_{2.5}$ was collected onto quartz microfiber filters $(20.3 \times 25.4 \mathrm{~cm}$, PALL, USA) for continuous $24 \mathrm{~h}$ using a $\mathrm{PM}_{2.5}$ high-volume air sampler (T-6070C, Tisch Environmental, USA) on the roof of the Research Building on the campus of Xinxiang Medical University $\left(113.50^{\circ} \mathrm{E}\right.$, $35.21^{\circ} \mathrm{N}$ ) from November 2015 to March 2016 on non-rainy days, with no large surrounding industries but heavy traffic, indicating a characteristic urban environment. The nearest main roads (Xinzhong Street and Jinsui Street) are about $120 \mathrm{~m}$ west and $150 \mathrm{~m}$ north of the sampling site, respectively. The flow rate through the impactor with a size cut at $2.5 \mu \mathrm{m}$ was $40 \mathrm{cfm}$ and continuously monitored data was recorded on a ribbon of paper. The impactor was calibrated using the flow calibrating meter (TE-5028, Tisch Environmental, USA) once a month following the manufacturer's instructions. Before and after $\mathrm{PM}_{2.5}$ extraction, the quartz filters were equilibrated in a conditioning container at $22{ }^{\circ} \mathrm{C}$ and at $33 \%$ relative humid for $48 \mathrm{~h}$ before weighing on a microbalance (Mettler Toledo XS205, Switzerland). The $\mathrm{PM}_{2.5}$ was extracted from the filters through a 15 min sonication for three times with 2 min intervals. The $\mathrm{PM}_{2.5}$ was recovered through vacuum freeze-drying procedure and used for the intratracheal instillation. To specify the physicochemical properties of $\mathrm{PM}_{2.5}$, the contents of anion and metal components in $\mathrm{PM}_{2.5}$ were determined with ion chromatography (ICS-90, Dionex, USA) and inductive coupled plasma emission spectrometer (iCAP RQ, Thermo Fisher, USA), respectively.

\section{$\mathrm{PM}_{2.5}$ exposure and intervention}

The dose of $\mathrm{PM}_{2.5}$ used for rat intratracheal instillation in this study was determined based on the exposure conditions of the city residents in Xinxiang: 1) The concentration of $\mathrm{PM}_{2.5}$ could exceed $500 \mu \mathrm{g} / \mathrm{m}^{3}$ in Xinxiang 
city on a heavy polluted day; 2) The respiratory volume is $0.13 \mathrm{~L} / \mathrm{min} / \mathrm{kg}$ for humans [23], and the deposition rate of $\mathrm{PM}_{2.5}$ is around $40 \%$ in a human lung [24]. Based on these parameters, it is estimated that the daily $(8 \mathrm{~h})$ deposition of $\mathrm{PM}_{2.5}$ in a human lung is approximately $15.6 \mu \mathrm{g} / \mathrm{kg}$ body weight. Given that the conversion factor of instilled dose from humans to rats is around 10 [25], the equivalent dose for a rat is $156 \mu \mathrm{g} / \mathrm{kg}$. In a preliminary study, we noticed that $\mathrm{PM}_{2.5}$ at $1 \mathrm{mg} / \mathrm{kg}$ only induced mild toxicity. To achieve a proper margin for evaluating the inhibitory effect of fish oil and Vit $\mathrm{E}$ on $\mathrm{PM}_{2.5}$-induced lung inflammation, we adjusted the dose of instilled $\mathrm{PM}_{2.5}$ in this study to $10 \mathrm{mg} / \mathrm{kg}$ referring to a similar study in which 3,10 , or $30 \mathrm{mg} / \mathrm{kg}$ of $\mathrm{PM}_{2.5}$ was used to assess $\mathrm{PM}_{2.5}$-induced cardiovascular toxicity [26]. Based on the recommended daily doses of fish oil and Vit E for an adult male and the conversion coefficient between man and rat, $150 \mathrm{mg} / \mathrm{kg}$ and $75 \mathrm{mg} / \mathrm{kg}$ body weight were used as the gavage dose of fish oil and Vit E, respectively, in this study.

Sixty four male SD rats were randomly divided into four groups according to the intervention: control group, corn oil (diluent) group, fish oil group, and Vit E group. In each group $(n=16)$, an equal number of the rats was intratracheally instilled with phosphate buffered saline (PBS) and $\mathrm{PM}_{2.5}$, respectively. The rats were gavaged with saline, corn oil $(5 \mathrm{ml} / \mathrm{kg})$, fish oil $(150 \mathrm{mg} / \mathrm{kg})$, and Vit E $(75 \mathrm{mg} / \mathrm{kg})$, respectively, once a day for 21 consecutive days prior to intratracheal instillation of $\mathrm{PM}_{2.5}$ $(10 \mathrm{mg} / \mathrm{kg})$ every other day for a total of 3 times. Normal saline was used as negative control. Corn oil was used as the diluent for fish oil and Vit E.

\section{Analysis of bronchoalveolar lavage fluids (BALFs)}

The BALFs were collected as previously described [21]. Briefly, the rats were sacrificed $24 \mathrm{~h}$ after the final intratracheal instillation of $\mathrm{PM}_{2.5}$ suspension. The left lung was lavaged with ice-cold saline $(10 \mathrm{ml}, 5 \mathrm{ml}$ per time). The recovery BALFs was approximately $80 \%$ of the amount instilled. BALFs were pooled and centrifuged at $1500 \mathrm{rpm}$ for $20 \mathrm{~min}$ at $4{ }^{\circ} \mathrm{C}$. The supernatants and cell pellets were collected separately. The total number of cells was counted under a light microscope.

\section{Histological analysis}

The right lung was routinely fixed, embedded in paraffin, cut into $5 \mu \mathrm{m}$ sections in thickness and stained with haematoxylin and eosin (H-E). The histological and morphological alterations of lung tissues were observed under a light microscope. As described above, the histology was done on a subset of non-lavaged animals through inflation fixation in accordance with the American Thoracic Society/European Respiratory Society guidelines [27].

\section{Examination of lung damage}

$\mathrm{LDH}$ is a stable cytoplasmic enzyme that is present in all cells. Once plasma membrane of cell is damaged, LDH will be released instantly to the outside of the cells. Levels of LDH and total proteins in the supernatants of BALFs are proportional to the severity of lung damage and determined by LDH activity and BCA Protein Assay kit, respectively.

\section{Determination of inflammatory cytokines with ELISA}

The blood of rats was collected and centrifuged at $684 \mathrm{~g}$ for $10 \mathrm{~min}$ at $4{ }^{\circ} \mathrm{C}$ to obtain serum. TNF- $\alpha$, IL-1 $\beta$, CRP and IL- 6 are bio-markers of lung and systemic inflammation. Levels of TNF- $\alpha$ and IL- $1 \beta$ in BALFs as well as CRP and IL- 6 in serum were determined by ELISA according to the instructions supplied by the kit's manufacturer.

\section{Analysis of oxidative stress in lung}

Superoxide dismutase (SOD) is a ubiquitous antioxidant enzyme that protects organisms from oxidative stress [28]. In contrast, 8 -epi-PGF $2 \alpha$ is a product of oxidative stress. Levels of SOD and 8-epi-PGF2 $\alpha$ were used to evaluate oxidative stress using an SOD activity assay kit and 8-epi-PGF2 $\alpha$ ELISA kit, respectively.

\section{Statistical analysis}

ANOVA was used for multiple comparisons followed by LSD analysis. The data were presented as mean \pm standard deviation (SD) and $p$-value less than 0.05 was considered statistically significant. Statistical analysis was performed using SPSS21.0.

\section{Results}

Water-soluble chemical composition of $\mathrm{PM}_{2.5}$

The concentrations of chemical constituents of $\mathrm{PM}_{2.5}$ are shown in Table 1. The concentrations of 11 metals (Ca, Mg, Zn, Mn, Al, Cu, Ni, Cr, Pb, Cd, Se) and seven water-soluble anions $\left(\mathrm{F}^{-}, \mathrm{Ac}^{-}, \mathrm{Br}^{-}, \mathrm{Cl}^{-}, \mathrm{NO}_{3}{ }^{-}, \mathrm{HPO}_{4}{ }^{2-}\right.$, $\mathrm{SO}_{4}{ }^{2-}, \mathrm{NO}_{2}{ }^{-}$) were determined in the samples.

\section{Fish oil ameliorates $\mathrm{PM}_{2.5}$-induced lung damage}

As shown in Fig. 1a, a large portion of $\mathrm{PM}_{2.5}$ particles were seen scattered and a small portion were seen to be aggregated in a microscopic evaluation of $\mathrm{PM}_{2.5}$ suspension. Figure $1 \mathrm{~b}$ showed that $\mathrm{PM}_{2.5}$ was mainly deposited in the alveolar area after intratracheal instillation, and that the particles were phagocytized by alveolar macrophages. Thus, these results demonstrate that $\mathrm{PM}_{2.5}$ is well dispersed in the suspension, which can reach alveolar areas and interact with alveolar macrophages.

Fig. 2a, c, e, and g showed the architecture of lung tissues from rats only instilled with vehicle controls, including PBS, corn oil, fish oil and Vit E, respectively. 
Table 1 Average mass concentration of soluble anion and metals in $\mathrm{PM}_{2.5}$

\begin{tabular}{llll}
\hline Metals & $\begin{array}{l}\text { Mass Concentration } \\
\left(\mu \mathrm{g} / \mathrm{mg} \mathrm{PM}_{2.5}\right)\end{array}$ & Soluble lons & $\begin{array}{l}\text { Mass Concentration } \\
\left(\mu \mathrm{g} / \mathrm{mg} \mathrm{PM} \mathrm{PM}_{2.5}\right)\end{array}$ \\
\hline $\mathrm{Ca}$ & 21.83 & $\mathrm{~F}^{-}$ & 4.14 \\
$\mathrm{Mg}$ & 3.62 & $\mathrm{Ac}^{-}$ & 22.80 \\
$\mathrm{Zn}$ & 4.38 & $\mathrm{Cl}^{-}$ & 45.56 \\
$\mathrm{Mn}$ & 0.20 & $\mathrm{NO}_{3}{ }^{3-}$ & 0.85 \\
$\mathrm{Al}$ & 4.55 & $\mathrm{Br}^{-}$ & 0.51 \\
$\mathrm{Cu}$ & 0.17 & $\mathrm{NO}_{3}{ }^{-}$ & 236.41 \\
$\mathrm{Ni}$ & 0.09 & $\mathrm{HPO}_{4}{ }^{2-}$ & 180.22 \\
$\mathrm{Cr}$ & 0.69 & $\mathrm{SO}_{4}{ }^{2-}$ & 0.83 \\
$\mathrm{~Pb}$ & 0.33 & & \\
$\mathrm{Cd}$ & 0.01 & & \\
$\mathrm{Se}$ & 0.28 & & \\
\hline
\end{tabular}

Overall, these tissues showed intact lung architecture. In contrast, the lung tissues instilled with $\mathrm{PM}_{2.5}$ alone (Fig. 2b) induced severe inflammatory damage, represented as infiltration of inflammatory cells (macrophages and lymphocytes) into airways and surrounding tissues. Similar alterations were seen in the lung tissues instilled with $\mathrm{PM}_{2.5}$ in the corn oil group (Fig. 2d). In contrast, the inflammation appeared lessened in the lung tissues instilled with $\mathrm{PM}_{2.5}$ in the fish oil group (Fig. 2f) but not in the corn oil group (Fig. 2h). The

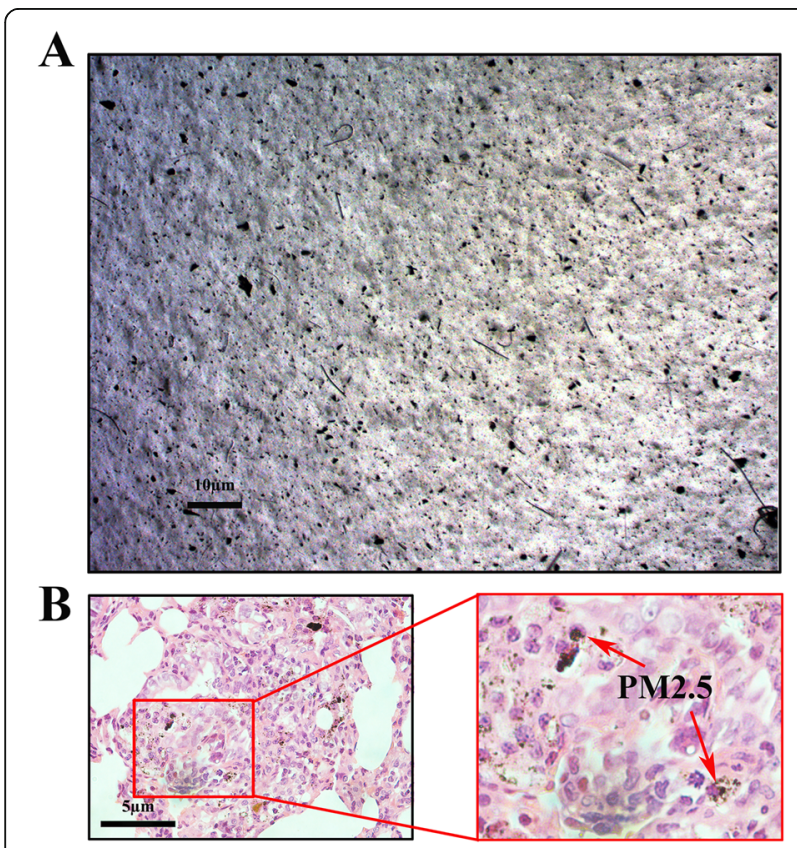

Fig. $1 \mathrm{PM}_{2.5}$ deposition in lungs of rats. a Fine particulate in $\mathrm{PM}_{2.5}$ suspension were observed using an optical microscope, bars $10 \mu \mathrm{m}$; (b) Deposition of $\mathrm{PM}_{2.5}$ in the deep lungs of rat, bars $5 \mu \mathrm{m}$. Red arrows showed that $\mathrm{PM}_{2.5}$ was phagocytosed by macrophage dark matter (coalesced $\mathrm{PM}_{2.5}$ ) in the infiltrating cells in the Vit E/PM 2.5 exposed lungs was observed (Fig. 2h). In summary, these results indicate that exposure to $\mathrm{PM}_{2.5}$ induces pronounced lung inflammation, which is ameliorated by supplementation with fish oil.

The inflammatory alterations of rat lungs instilled with $\mathrm{PM}_{2.5}$ were accompanied by biochemical changes in BALF analytes, including TP and LDH, indicative of lung injury. As shown in Fig. 3, $\mathrm{PM}_{2.5}$ instillation increased the levels of TP and LDH in the BALFs $(p<0.05)$. This effect of $\mathrm{PM}_{2.5}$ was significantly blocked by supplementation of rats with fish oil $(p<0.05)$, indicating that fish oil markedly ameliorated $\mathrm{PM}_{2.5}$-induced lung damage. In contrast, Vit E did not show significant inhibition on $\mathrm{PM}_{2.5}$-induced lung damage.

\section{Fish oil reduces $\mathrm{PM}_{2.5}$-induced lung and systemic inflammatory responses}

Total cell counts and inflammatory mediators are pivotal biomarkers of lung and systemic inflammatory responses $[29,30]$. As shown in Fig. 4a, $\mathrm{PM}_{2.5}$ instillation significantly increased the total number of infiltrated cells, which was blocked by pre-gavage with fish oil but not with Vit E. Moreover, $\mathrm{PM}_{2.5}$ instillation significantly increased the levels of TNF- $\alpha$ and IL- $1 \beta$ in BALFs $(p<$ $0.05)$, and CRP and IL-6 in serum $(p<0.05)$, as shown in Fig. 4b, c, d, and e. Supplementation with fish oil significantly blocked $\mathrm{PM}_{2.5}$-induced expression of TNF- $\alpha, \mathrm{CRP}$, and IL-6 $(p<0.05)$. In contrast, supplementation with Vit E only partially decreased $\mathrm{PM}_{2.5}$-induced IL- $1 \beta$ and TNF- $\alpha$ (Fig. $4 \mathrm{~b}$ and c).

\section{Effect of fish oil and Vit E on $\mathrm{PM}_{2.5}$-induced oxidative stress in lungs}

Oxidative stress has been proposed to be involved in $\mathrm{PM}_{2.5}$-induced lung toxicity [31]. Levels of SOD and 8-epi-PGF2 $\alpha$ in BALFs were used to indirectly assess oxidative stress in rat lungs. As shown in Fig. 5a, $\mathrm{PM}_{2.5}$ instillation significantly decreased the levels of the antioxidant enzyme SOD, which was inhibited by supplementation with fish oil $(p<0.05)$, but not with Vit E. Instillation with $\mathrm{PM}_{2.5}$ markedly increased the levels of 8 -epi-PGF2 $\alpha$ in rat lung, a biomarker of oxidative stress (Fig. 5b). Interestingly, dietary supplementation with fish oil or Vit E increased the levels of 8-epi-PGF2 $\alpha$ in both control and $\mathrm{PM}_{2.5}$ groups.

\section{Discussion}

A plethora of epidemiological studies have demonstrated that exposure to $\mathrm{PM}_{2.5}$ is positively associated with increased prevalence of cardiovascular and respiratory disease $[29,32]$. According to the global burden of disease study, 1.1 million people died from $\mathrm{PM}_{2.5}$ in 2015 in China [6]. In addition to the mortality costs, many areas of China 

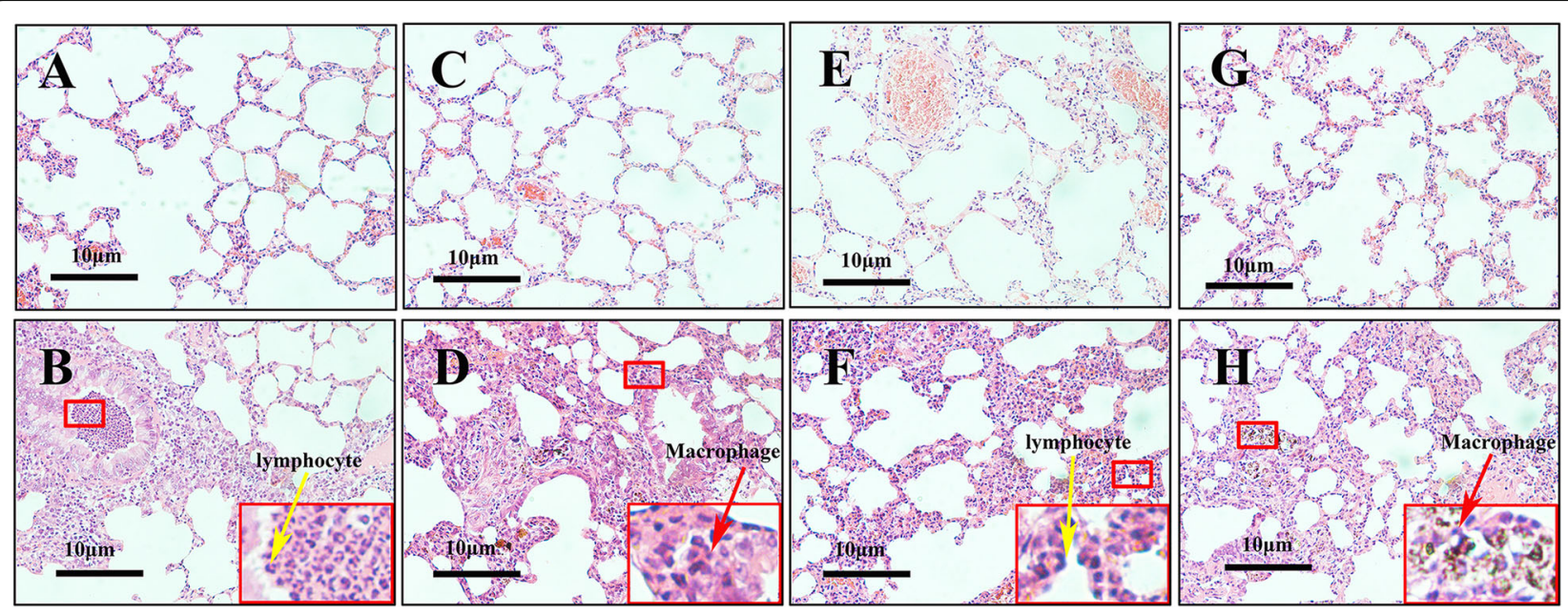

Fig. $2 \mathrm{PM}_{2.5}$-induced infiltration of inflammatory cells in lungs was ameliorated by fish oil. Pathological changes and morphological alteration of lung tissues were evaluated by HE staining. a PBS group; (b) PM $_{25}$ alone group; (c) corn oil group; (d) corn oil + PM 25 group; (e) fish oil group; (f) fish oil + PM 2.5 group; (g) Vit E group; (h) Vit E + PM 2.5 group. Yellow and red arrows showed infiltration of inflammatory cells (lymphocyte and

macrophage), bars $10 \mu \mathrm{m}$

have suffered from severe haze pollution recently, which greatly affects human health and daily life [1]. $\mathrm{PM}_{2.5}$ pollution in China, mainly from coal burning and motor vehicles emission, is linked to the rapid economic development. It is predicted that heavy $\mathrm{PM}_{2.5}$ pollution (haze weather) will occur frequently in some areas of China for the foreseeable future. Therefore, characterization of $\mathrm{PM}_{2.5}$ toxicity and potential mechanisms, and identification of effective interventional measures are of great significance to protect susceptible people against $\mathrm{PM}_{2.5}$ toxicity. The present study examined the inhibitory effect of fish oil and Vit E on $\mathrm{PM}_{2.5}$-induced lung injury and inflammation, showing that that fish oil supplementation ameliorates $\mathrm{PM}_{2.5}$-induced lung toxicity.
Inflammatory mediators, such as TNF- $\alpha$ and IL- $1 \beta$, are seen to be elevated and are believed to play an important role in $\mathrm{PM}_{2.5}$-induced lung toxicity $[5,33,34]$. IL-1 $\beta$, an important regulator of innate and acquired immune responses, is capable of recruiting inflammatory cells [35]. The function of TNF- $\alpha$ is associated with cell recruitment and leukocyte activation, leading to local inflammatory responses [36, 37]. Our previous study has demonstrated that $\mathrm{PM}_{2.5}$ induces lung inflammation, represented as increased levels of TP, IL-1 $\beta$, IL-18, and cell number in the BALFs of BALB/c mice [21]. The study is further supported by the results from this study, showing that exposure to $\mathrm{PM}_{2.5}$ increases the levels of TP, LDH, IL-1 $\beta$ and total inflammatory cell number in the BALFs of rats.
A

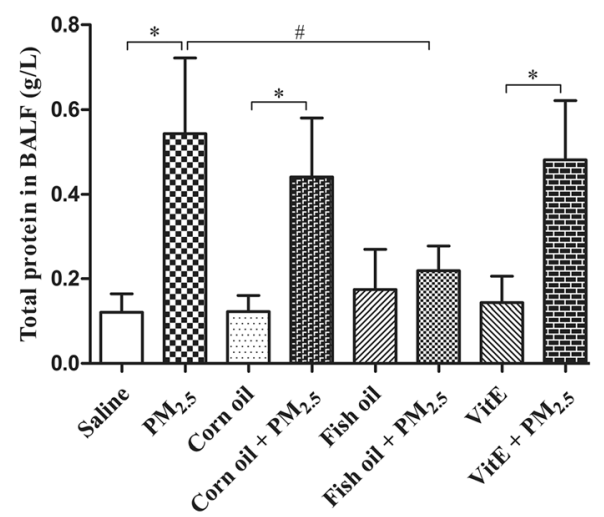

B

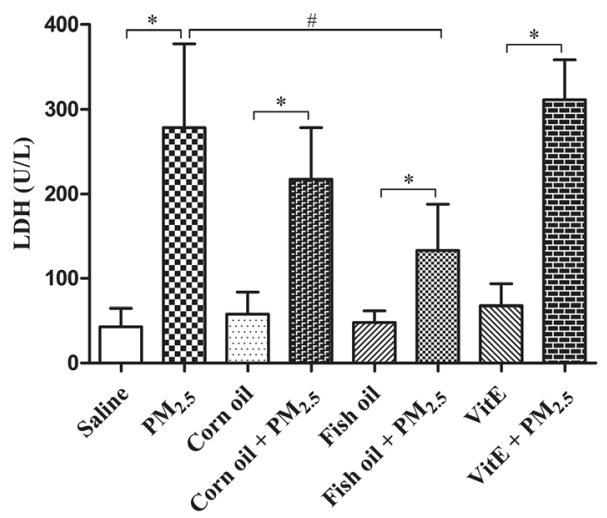

Fig. 3 Fish oil supplementation inhibits $P M_{2.5}$-induced TP and LDH release from rat lungs. Total protein (a) and LDH (b) were measured by using BCA protein assay kit and LDH kit, separately. All values represent the mean $\pm \mathrm{SD}(n=8) .{ }^{*} p<0.05$ compared with corresponding control group; $\# p<0.05$ compared with $\mathrm{PM}_{2.5}$ group 

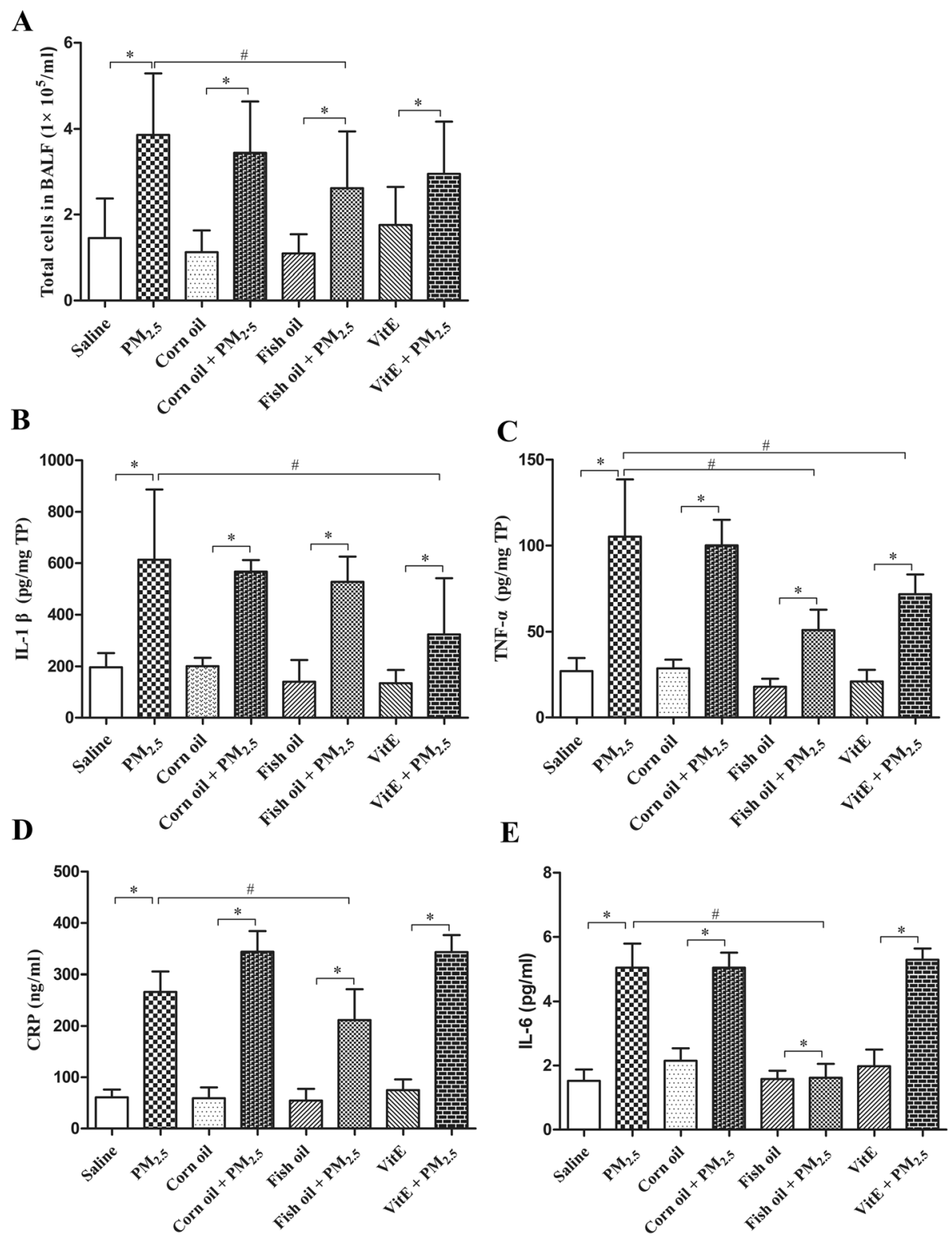

Fig. 4 Effect of fish oil or Vit E supplementation on PM 2.5 -induced TNF- $\alpha$ and IL-1 $\beta$ release from rat lungs and CRP and IL-6 release in serum. Total inflammatory cell counts (a) was counted under light microscope. TNF-a (b), IL-1 $\beta$ (c), CRP (d) and IL-6 (e) were determined by ELISA. All values represent the mean $\pm S D(n=8) .{ }^{*} p<0.05$ compared with corresponding control group; ${ }^{\#} p<0.05$ compared with $\mathrm{PM}_{2.5}$ group

In addition to lung inflammation, the results from this study also indicated that $\mathrm{PM}_{2.5}$ exposure induced pronounced increase in the levels of serum CRP and IL-6, indicative of systemic inflammation. However, the molecular mechanisms responsible for $\mathrm{PM}_{2.5}$-induced pulmonary and systemic inflammation remain unclear. Oxidative stress and inflammation are thought to play a critical role in $\mathrm{PM}_{2.5}$-induced lung diseases [29]. Oxidative stress is related to a biochemical imbalance process in which production of ROS exceeds the natural antioxidant capacity. ROS play an important role in PM-induced lung injury [38]. 8-epi-PGF2 $\alpha$ has been used to indirectly assess oxidative stress [39]. SOD has been regarded as an important cellular defense for scavenging ROS [40, 41]. Therefore, the levels of SOD and 8-epi-PGF2 $\alpha$ are regarded as a sensitive indicator of oxidative stress. In this study, exposure to $\mathrm{PM}_{2.5}$ decreases the levels of SOD but increased the levels of 8-epi-PGF2 $\alpha$ in the BALFs, indicating that exposure to $\mathrm{PM}_{2.5}$ induces oxidative stress. The mechanisms underlying $\mathrm{PM}_{2.5}$-induced oxidative stress may be related to its chemical components, such as metals. In the previous study, we demonstrated that $\mathrm{PM}_{2.5}$ samples from different seasons rendered varied cytotoxicity (unpublished data) and the metallic components and 

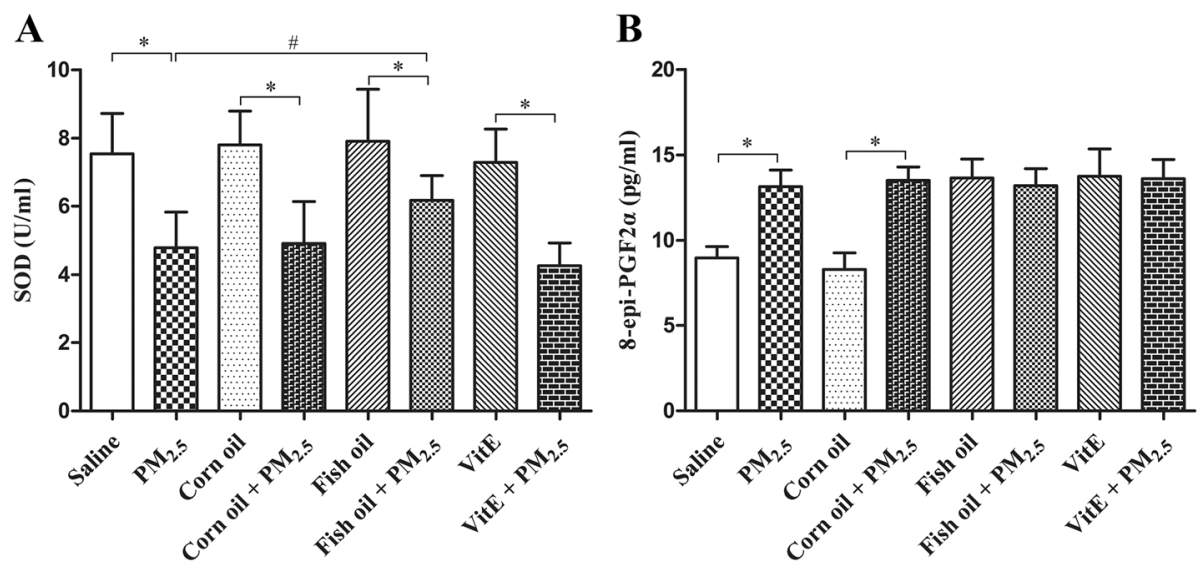

Fig. 5 Fish oil supplementation blocks $P_{2} M_{25}$-induced lung oxidative stress. SOD and 8-epi-PGF2a were measured by using superoxide dismutase detect kit and 8-epi-PGF2a ELISA kit. All values represent the mean \pm SD $(n=8) .{ }^{*} p<0.05$ compared with corresponding control group; ${ }^{\#} p<0.05$ compared with $\mathrm{PM}_{2.5}$ group

oxidative stress seemed to play an important role in $\mathrm{PM}_{2.5}$-induced lung inflammatory response [42].

Inflammation and oxidative stress are critical events involved in $\mathrm{PM}_{2.5}$-induced adverse health effects. Given the anti-inflammatory and anti-oxidant properties of fish oil and Vit E, it is therefore envisioned that the dietary supplementation with fish oil and Vit E may act against $\mathrm{PM}_{2.5}$-induced lung toxicity. The recommended daily doses of fish oil and Vit E are $25 \mathrm{mg} / \mathrm{kg}$ and $14 \mathrm{mg} / \mathrm{kg}$ body weight for an adult male, respectively, according to the 2016 Chinese guideline for the management of dyslipidemia in adults. Pharmacological experiments show that the conversion coefficient between man and rat is 6.17. Therefore, $150 \mathrm{mg} / \mathrm{kg}$ and $75 \mathrm{mg} / \mathrm{kg}$ body weight were used as the gavage dose of fish oil and Vit E, respectively. The results from this study showed that fish oil supplementation significantly ameliorated $\mathrm{PM}_{2.5}$-induced lung damage and inflammation. Previous studies have shown that fish oil and Vit E have beneficial effect on ameliorating inflammation and oxidative stress [22]. For instance, omega-3 PFAs and Vit E decrease levels of malondialdehyde (MDA), ROS, IL-6, and TNF- $\alpha$ but increase SOD activity in $\mathrm{PM}_{2.5}$-exposed vascular endothelial cells [43]. Consistent with this study, other in vivo studies have reported that supplementation with omega-3 PFAs or Vit E inhibits $\mathrm{PM}_{2.5}$-induced cardiovascular injury in rats through regulation of inflammatory mediator expression and anti-oxidative activity [35, 44]. However, in this study Vit E did not significantly affect the $\mathrm{PM}_{2.5}$-induced lung injury (i.e., protein leak or LDH), inflammatory changes (i.e., cellular infiltration, CRP and IL-6), or oxidative stress (i.e., SOD and 8-epi-PGF2 $\alpha$ ), only partially attenuated the $\mathrm{PM}_{2.5}$-induced increases in IL-1 $\beta$ and TNF- $\alpha$. These discrepancies may be partly explained by the differences in the dosage adequacy and isoforms of Vit $\mathrm{E}$ (i.e., $\alpha$-tocopherol and $\gamma$-tocophercol), target tissues and biological parameters examined in these studies [43-46]. In addition, the way exogenous antioxidants are integrated into the physiological antioxidative defense systems may also determine their effectiveness [46].

The exact mechanisms for fish oil inhibition of $\mathrm{PM}_{2.5}$-induced lung inflammation have not been fully uncovered. Omega-3 PFAs as the effective component of fish oil, present immune-modulated, anti-inflammatory and anti-oxidant properties [47, 48]. They can effectively improve antioxidant metabolism and reduce the lipid peroxidation $[49,50]$. Furthermore, it has been reported that omega-3 PFAs block inflammation and metabolic disorder through inhibition of pyrin domain-containing 3 (NLRP3) inflammasome activation [51]. The inflammasome, a central regulator of innate immunity and inflammation, promotes the maturation and release of several pro-inflammatory cytokines, including IL-1 $\beta$, IL-18, and IL-33 [52]. ROS is regarded as the crucial elements for NLRP3 activation [53]. Exposure to $\mathrm{PM}_{2.5}$ has been shown to activate inflammasome and increase levels of ROS and IL-1 $\beta$ [5]. Inhibition of the NLRP3/ Caspase1 pathway attenuates the generation of ROS and IL-1 $\beta$ [5]. Thus, modulation of NLRP3/Caspase1 pathway has been proposed to be another potential mechanism for fish oil inhibition of $\mathrm{PM}_{2.5}$-induce lung toxicity. Interestingly, dietary supplementation with fish oil or Vit $E$ elevated the background levels of 8-epi-PGF2 $\alpha$ in this study, implying that fish oil or Vit E increases oxidative stress. These results are consistent with previous observations that long-term intake of fish oil increases oxidative stress in women and in senescence-accelerated mice $[54,55]$. The underlying mechanisms remain unclear. A previous study reported that high dose Vit E supplementary intake induced lipid peroxidation [56]. The evidence indicates 
the importance of rational taking nutritional supplements and their potential toxicity.

It should be mentioned that limitations exist for this study using intratracheal instillation for $\mathrm{PM}_{2.5}$ exposure. This approach involves a single bolus exposure of $\mathrm{PM}_{2.5}$ that is very different either toxicokinetically or toxicodynamically from inhalation exposure, the gold standard for evaluation of toxic effects of inhaled PM. It has been recently reported that with the same dose of nanoparticles the intratracheal instillation caused stronger and more persistent pulmonary inflammation compared with inhalation exposure [57].

\section{Conclusion}

Given that $\mathrm{PM}_{2.5}$ pollution is a persistent problem in China, it is rational to search for efficacious interventional strategies to protect public health against $\mathrm{PM}_{2.5}$ toxicity. The present study suggests that fish oil supplementation may ameliorate $\mathrm{PM}_{2.5}$-induced lung toxicity, but its clinical significance needs further examination.

\begin{abstract}
Abbreviations
8-epi-PGF2a: 8-epi-prostaglandin F2a; BALF: Bronchoalveolar Lavage Fluid; COPD: chronic obstructive pulmonary disease; CRP: C-reactive protein; DHA: docosahexaenoic acid; EPA: eicosapentaenoic acid; IL-1 $\beta$ : interleukin-1 $\beta$; LDH: Lactate Dehydrogenase; NFKB: nuclear factor KB; NLRP3: pyrin domaincontaining 3; PFAs: polyunsaturated fatty acids; ROS: reactive oxygen species; SD: Sprague Dawley; SOD: superoxide dismutase; TNF-a: tumor necrosis factor-a; TP: total protein; VitE: Vitamin E
\end{abstract}

\section{Acknowledgements}

We greatly appreciate Dr. James M. Samet for revision of this manuscript.

\section{Funding}

This work was supported by a grant from the National Natural Science Foundation of China (81573112; 81373030)

\section{Availability of data and materials}

The datasets generated during and/or analyzed during the current study are available from the corresponding author on reasonable request.

\section{Authors' contributions}

W Wu designed the study. H Li and J Li carried out the experimental work analyzed the data, and drafted the manuscript. All authors read and approved the final manuscript.

\section{Ethics approval and consent to participate}

The animal experiments were reviewed and approved by the Experimental Animal Ethics Committee of Xinxiang Medical University.

\section{Consent for publication}

All the authors declare that they are consent for the publication.

\section{Competing interests}

The authors declare that there is no conflict of interests.

\section{Publisher's Note}

Springer Nature remains neutral with regard to jurisdictional claims in published maps and institutional affiliations.
Received: 28 December 2018 Accepted: 7 April 2019

Published online: 16 April 2019

\section{References}

1. Brunekreef B, Holgate ST. Air pollution and health. Lancet. 2002;360:1233-42.

2. Xu P, Chen Y, Ye X. Haze, air pollution, and health in China. Lancet. 2013; 382:2067.

3. Ma Z, Hu X, Sayer AM, Levy R, Zhang Q, Xue Y, Tong S, Bi J, Huang L, Liu Y. Satellite-based spatiotemporal trends in PM2.5 concentrations: China, 20042013. Environ Health Perspect. 2016;124:184-92.

4. van Donkelaar A, Martin RV, Brauer M, Boys BL. Use of satellite observations for long-term exposure assessment of global concentrations of fine particulate matter. Environ Health Perspect. 2015;123:135-43.

5. Zheng $R$, Tao L, Jian H, Chang Y, Cheng Y, Feng Y, Zhang H. NLRP3 inflammasome activation and lung fibrosis caused by airborne fine particulate matter. Ecotoxicol Environ Saf. 2018;163:612-9.

6. Cohen AJ, Brauer M, Burnett R, Anderson HR, Frostad J, Estep K, Balakrishnan K, Brunekreef B, Dandona L, Dandona R, et al. Estimates and 25-year trends of the global burden of disease attributable to ambient air pollution: an analysis of data from the global burden of diseases study 2015. Lancet. 2017;389:1907-18.

7. Schwarze PE, Ovrevik J, Lag M, Refsnes M, Nafstad P, Hetland RB, Dybing E. Particulate matter properties and health effects: consistency of epidemiological and toxicological studies. Hum Exp Toxicol. 2006:25:559-79.

8. Etzel RA. How environmental exposures influence the development and exacerbation of asthma. Pediatrics. 2003;112:233-9.

9. Wright J, Ji Z, Geng X, Ding Y. Ongoing progress in cleaning China's air: A novel outlook into pollution. 2016:1:43.

10. Laden F, Hart JE, Smith TJ, Davis ME, Garshick E. Cause-specific mortality in the unionized U.S. trucking industry. Environ Health Perspect. 2007;115:1192-6.

11. Paulin L, Hansel N. Particulate air pollution and impaired lung function. F1000Res. 2016:5.

12. Alfaro-Moreno E, Nawrot TS, Nemmar A, Nemery B. Particulate matter in the environment: pulmonary and cardiovascular effects. Curr Opin Pulm Med. 2007;13:98-106

13. Calder PC. The 2008 ESPEN sir David Cuthbertson lecture: fatty acids and inflammation--from the membrane to the nucleus and from the laboratory bench to the clinic. Clin Nutr. 2010;29:5-12.14.

14. Lobo BW, Lima CK, Teixeira MS, Silva NL, Takiya CM, Ramos MF, Miranda AL, Dellamora-Ortiz GM. Fish oil attenuates persistent inflammatory pain in rats through modulation of TNF-alpha and resolvins. Life Sci. 2016;152:30-7.

15. Dong L, Zou H, Yuan C, Hong YH, Kuklev DV, Smith WL. Different fatty acids compete with arachidonic acid for binding to the allosteric or catalytic subunits of cyclooxygenases to regulate Prostanoid synthesis. J Biol Chem. 2016:291:4069-78.

16. Li MY, Wang YY, Cao R, Hou XH, Zhang L, Yang RH, Wang F. Dietary fish oil inhibits mechanical allodynia and thermal hyperalgesia in diabetic rats by blocking nuclear factor-kappaB-mediated inflammatory pathways. J Nutr Biochem. 2015:26:1147-55.

17. Meydani M, Vitamin E. Lancet. 1995;345:170-5

18. Niki E, Traber MG. A history of vitamin E. Annals of Nutrition \& Metabolism. 2012;61:207-12.

19. Burton GW, Cheeseman KH, Doba T, Ingold KU, Slater TF. Vitamin E as an antioxidant in vitro and in vivo. CIBA Found Symp. 1983;101:4-18.

20. Palace VP, Hill MF, Farahmand F, Singal PK. Mobilization of antioxidant vitamin pools and hemodynamic function after myocardial infarction. Circulation. 1999:99:121-6.

21. Jin $Y$, Wu W, Zhang W, Zhao Y, Wu Y, Ge G, Ba Y, Guo Q, Gao T, Chi X, et al. Involvement of EGF receptor signaling and NLRP12 inflammasome in fine particulate matter-induced lung inflammation in mice. Environ Toxicol. 2017:32:1121-34.

22. Tong $\mathrm{H}$. Dietary and pharmacological intervention to mitigate the cardiopulmonary effects of air pollution toxicity. Biochim Biophys Acta. 2016:1860:2891-8

23. Frohlich E, Mercuri A, Wu S, Salar-Behzadi S. Measurements of deposition, lung surface area and lung fluid for simulation of inhaled compounds. Front Pharmacol. 2016;7:181

24. Oberdorster G, Yu CP. Lung dosimetry--considerations for noninhalation studies. Exp Lung Res. 1999;25:1-6. 
25. Phillips JE. Inhaled efficacious dose translation from rodent to human: a retrospective analysis of clinical standards for respiratory diseases. Pharmacol Ther. 2017;178:141-7.

26. Pei $Y$, Jiang $R$, Zou $Y$, Wang $Y$, Zhang $S$, Wang $G$, Zhao J, Song W. Effects of fine particulate matter (PM2.5) on systemic oxidative stress and cardiac function in $\operatorname{ApoE}(-/-)$ mice. Int J Environ Res Public Health. 2016;13.

27. Hsia CC, Hyde DM, Ochs M, Weibel ER. An official research policy statement of the American Thoracic Society/European Respiratory Society: standards for quantitative assessment of lung structure. Am J Respir Crit Care Med. 2010;181:394-418.

28. Zelko IN, Mariani TJ, Folz RJ. Superoxide dismutase multigene family: a comparison of the CuZn-SOD (SOD1), Mn-SOD (SOD2), and EC-SOD (SOD3) gene structures, evolution, and expression. Free Radic Biol Med. 2002;33:337-49.

29. Kim HJ, Choi MG, Park MK, Seo YR. Predictive and prognostic biomarkers of respiratory diseases due to particulate matter exposure. J Cancer Prev. 2017;22:6-15.

30. Rider P, Carmi Y, Guttman O, Braiman A, Cohen I, Voronov E, White MR, Dinarello CA, Apte RN. IL-1alpha and IL-1beta recruit different myeloid cells and promote different stages of sterile inflammation. J Immunol. 2011:187:4835-43.

31. Mazzoli-Rocha F, Fernandes S, Einicker-Lamas M, Zin WA. Roles of oxidative stress in signaling and inflammation induced by particulate matter. Cell Biol Toxicol. 2010;26:481-98.

32. Pope CA 3rd, Burnett RT, Thun MJ, Calle EE, Krewski D, Ito K, Thurston GD. Lung cancer, cardiopulmonary mortality, and long-term exposure to fine particulate air pollution. Jama. 2002;287:1132-41.

33. van Eeden SF, Yeung A, Quinlam K, Hogg JC. Systemic response to ambient particulate matter: relevance to chronic obstructive pulmonary disease. Proc Am Thorac Soc. 2005;2:61-7.

34. Huang KL, Liu SY, Chou CC, Lee YH, Cheng TJ. The effect of size-segregated ambient particulate matter on Th1/Th2-like immune responses in mice. PLOS One. 2017;12:e0173158.

35. Du X, Jiang S, Bo L, Liu J, Zeng X, Xie Y, He Q, Ye X, Song W, Zhao J. Combined effects of vitamin $E$ and omega-3 fatty acids on protecting ambient PM2.5-induced cardiovascular injury in rats. Chemosphere. 2017; 173:14-21.

36. Chen $T$, Zhang J, Zeng H, Zhang $Y$, Zhang $Y$, Zhou X, Zhao D, Feng $Y$, Zhou $H$. The impact of inflammation and cytokine expression of PM2.5 in AML. Oncol Lett. 2018;16:2732-40.

37. Arokiasamy S, Zakian C, Dilliway J, Wang W, Nourshargh S, Voisin MB. Endogenous TNFalpha orchestrates the trafficking of neutrophils into and within lymphatic vessels during acute inflammation. Sci Rep. 2017;7:44189.

38. Li N, Xia T, Nel AE. The role of oxidative stress in ambient particulate matterinduced lung diseases and its implications in the toxicity of engineered nanoparticles. Free Radic Biol Med. 2008;44(9):1689-1699.

39. Lawson JA, Rokach J, Fitzgerald GA. Isoprostanes: formation, analysis and use as indices of lipid peroxidation in vivo. J Biol Chem. 1999;274:24441-4

40. Bowler RP, Nicks M, Warnick K, Crapo JD. Role of extracellular superoxide dismutase in bleomycin-induced pulmonary fibrosis. Am J Physiol Lung Cell Mol Physiol. 2002;282:719-26.

41. Mccord JM, Fridovich I. The biology and pathology of oxygen radicals. Ann Intern Med. 1978;89:122-7.

42. Yan Z, Wang J, Li J, Jiang N, Zhang R, Yang W, Yao W, Wu W. Oxidative stress and endocytosis are involved in upregulation of interleukin-8 expression in airway cells exposed to PM2.5. Environ Toxicol. 2016;31:1869-78.

43. Bo L, Jiang $S$, Xie $Y$, Kan H, Song W, Zhao J. Effect of Vitamin E and Omega3 fatty acids on protecting ambient PM2.5-induced inflammatory response and oxidative stress in vascular endothelial cells. PLoS One. 2016;11: e0152216.

44. Guan L, Geng X, Shen J, Yip J, Li F, Du H, Ji Z, Ding Y. PM2.5 inhalation induces intracranial atherosclerosis which may be ameliorated by omega 3 fatty acids. Oncotarget. 2018;9:3765-78.

45. Hernandez M, Zhou H, Zhou B, Robinette C, Crissman K, Hatch G, Alexis NE, Peden D. Combination treatment with high-dose vitamin $C$ and alphatocopherol does not enhance respiratory-tract lining fluid vitamin C levels in asthmatics. Inhal Toxicol. 2009;21:173-81.

46. Suchankova J, Voprsalova M, Kottova M, Semecky V, Visnovsky P. Effects of oral alpha-tocopherol on lung response in rat model of allergic asthma. Respirology. 2006:11:414-21.
47. Zhang MJ, Spite M. Resolvins: anti-inflammatory and proresolving mediators derived from omega-3 polyunsaturated fatty acids. Annu Rev Nutr. 2012;32:203-27.

48. Fritsche K. Fatty acids as modulators of the immune response. Annu Rev Nutr. 2006:26:45-73.

49. Possamai FP, Junior SA, Parisotto EB, Moratelli AM, Inacio DB, Garlet TR, DalPizzol F, Filho DW. Antioxidant intervention compensates oxidative stress in blood of subjects exposed to emissions from a coal electric-power plant in South Brazil. Environ Toxicol Pharmacol. 2010:30:175-80.

50. Moreno JJ, Mitjavila MT. The degree of unsaturation of dietary fatty acids and the development of atherosclerosis (review). J Nutr Biochem. 2003;14:182-95

51. Yan Y, Jiang W, Spinetti T, Tardivel A, Castillo R, Bourquin C, Guarda G, Tian Z, Tschopp J, Zhou R. Omega-3 fatty acids prevent inflammation and metabolic disorder through inhibition of NLRP3 inflammasome activation. Immunity. 2013;38:1154-63.

52. Martinon F, Mayor A, Tschopp J. The inflammasomes: guardians of the body. Annu Rev Immunol. 2009;27:229-65.

53. Tschopp J, Schroder K. NLRP3 inflammasome activation: the convergence of multiple signalling pathways on ROS production? Nat Rev Immunol. 2010; 10:210-5.

54. Meydani M, Natiello F, Goldin B, Free N, Woods M, Schaefer E, Blumberg JB, Gorbach SL. Effect of long-term fish oil supplementation on vitamin E status and lipid peroxidation in women. J Nutr. 1991;121:484-91.

55. Tsuduki T, Honma T, Nakagawa K, Ikeda I, Miyazawa T. Long-term intake of fish oil increases oxidative stress and decreases lifespan in senescenceaccelerated mice. Nutrition. 2011;27:334-7.

56. Bowry WW, Ingold KU, Stocker R. Vitamin E in human low-density lipoprotein. When and how this antioxidant becomes a pro-oxidant. Biochem J. 1992;288(Pt 2):341-4.

57. Morimoto $Y$, Izumi H, Yoshiura $Y$, Fujishima K, Yatera K, Yamamoto K. Usefulness of Intratracheal instillation studies for estimating nanoparticleinduced pulmonary toxicity. Int J Mol Sci. 2016;17.

Ready to submit your research? Choose BMC and benefit from:

- fast, convenient online submission

- thorough peer review by experienced researchers in your field

- rapid publication on acceptance

- support for research data, including large and complex data types

- gold Open Access which fosters wider collaboration and increased citations

- maximum visibility for your research: over $100 \mathrm{M}$ website views per year

At $\mathrm{BMC}$, research is always in progress.

Learn more biomedcentral.com/submissions 